http://jmscr.igmpublication.org/home/ ISSN (e)-2347-176x ISSN (p) 2455-0450 crossref DOI: https://dx.doi.org/10.18535/jmscr/v8i2.13

\author{
(D) Journal Of Medical Science And Clinical Research \\ IGM Publication \\ An official Publication of IGM Publication
}

\title{
A Rare Case of Systemic Lupus Erythematosus with Gastric Antral Vascular Ectasia
}

\author{
Authors \\ Komali Dukka ${ }^{1}$, Yasodhamma $\mathbf{P}^{2}$, Manoj Boda ${ }^{3}$
}

\begin{abstract}
SYSTEMIC LUPUS ERYTHEMATOSUS is an autoimmune disease associated with auto antibody production. The inflammation produced by it can affect and damage many organ systems. The involvement of gastrointestinal system in SLE is well documented. The extent of involvement of git and the frequency of symptoms is being underestimated. Patients present with vague complaints such as abdominal pain, nausea, upper GI bleed with non-specific physical examination findings and inconclusive diagnostic tests and serologic analysis. In SLE diagnosis should be evoked, when clinical picture and endoscopic features are suggestive to present as upper GI bleed like peptic ulcer diease, gastric vascular ectasia

Keywords: SLE,Upper GI bleed, peptic ulcer disease, gastric vascular ectasia.
\end{abstract}

\section{Introduction}

SYSTEMIC LUPUS ERYTHEMATOSUS is an autoimmune disease associated with systemic inflammation affecting multiple organ systems and ultimately presenting in patients as a spectrum of disease with varied manifestations and multiple subtypes $^{[1]}$. SLE is a disease of female predominance with $90 \%$ patients being females especially women in the child bearing age group. The disease also effects males, children, women of non child bearing age group, but uncommon. There are various criteria to define SLE, of which American college of rheumatology criteria being the most common. As per the criteria 4 out of 11 findings are must to define SLE which include arthritis, cutaneous lesions, renal, pulmonary, cardiac or CNS involvement ${ }^{[2]}$

In SLE organs and cells undergo damage initially mediated by tissue binding auto antibodies and immune complexes. In most patients autoantibodies appear years before the manifestation of first clinical symptom

Systemic lupus erythematosus (SLE) is a multisystem autoimmune disease of protean manifestations and variable clinical behavior.

Clinically, it is an unpredictable, remitting and relapsing disease. The onset of the disease is acute or insidious. The disease may involve any organ in the body; principally effecting the skin, kidneys, serosal membranes, joints, and heart. ${ }^{[3]}$

Immunologically, the disease is associated with an enormous array of autoantibodies, classically including antinuclear antibodies (ANAs).

The clinical presentation of SLE is so variable. There are so many overlapping features with other autoimmune diseases (RA, polymyositis, and others). Hence it has been necessary to develop diagnostic criteria for SLE (table 1). The diagnosis is established by demonstration of four or more of the criteria during any interval of observation. 
SLE is a multisystem disease that is highly variable in clinical presentation. Typically, the patient is a young woman with some, but rarely all, of the following features: a butterfly rash over the face, fever, pain and swelling in one ormore peripheral joints (hands and wrists, knees, feet, ankles, elbows, shoulders), pleuritic chest pain, and photosensitivity.

In many patients, the SLE presentation is subtle and puzzling, presenting as a febrile illness of unknown origin, abnormal urinary findings, or joint disease masquerading as RA or rheumatic fever.

\section{Table 1}

\begin{tabular}{|l|c|}
\hline Malar rash & Renal disorder \\
\hline Discoid rash & Hematological \\
\hline Photosensitivity & Neurological \\
\hline Oral ulcers & Immunological \\
\hline Arthritis & Anti nuclear antibody \\
\hline Serositi & \\
\hline
\end{tabular}

ANAs are found in virtually $100 \%$ of patients, but an important point is that ANAs are not specific.

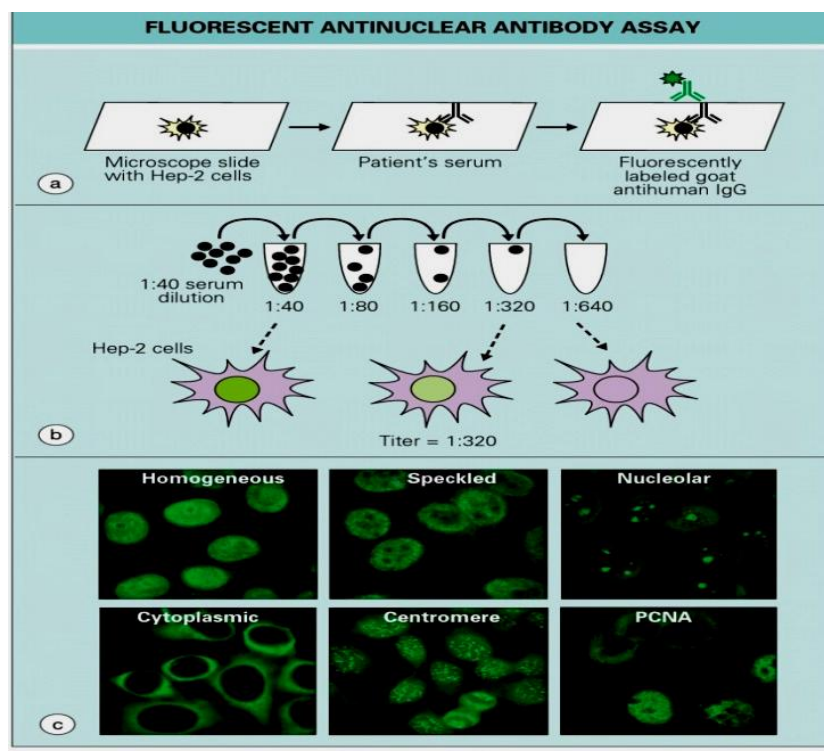

A variety of clinical findings may point toward renal involvement, including hematuria, red cell casts, proteinuria, and in some cases the classic nephrotic syndrome

\section{Laboratory evidence of some hematologic}

Derangement is common, and in some patients anemia or thrombocytopenia may be the presenting manifestation as well as the dominant clinical problem.

In some, neuropsychiatric manifestations including psychosis or convulsions, or coronary artery disease are prominent clinical problems.

Patients with SLE are also prone to infections, presumably because of their underlying immune dysfunction and treatment with immunosuppressive drugs.

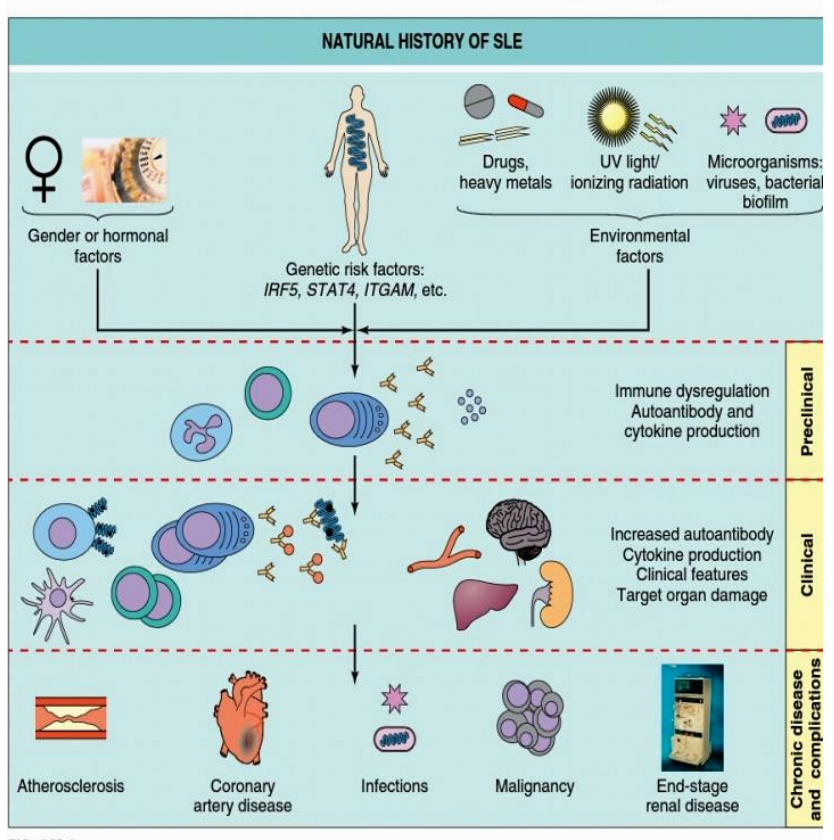

\section{Case Report}

A 35 year old male patient known case of SLE admitted in the hospital with a chief complaint of bouts of hematemesis since 2 days. He had total 10 bouts with each bout of approximately $50 \mathrm{ml}$. the patient also complains of generalized weakness and easy fatigability. He is not a known case of diabetes mellitus, hypertrension, chronic renal failure, liver failure. There is no history of CLD with portal hypertension, Acid peptic disease. He is not an alcoholic

On physical examination, he is moderately built, with BMI $30 \mathrm{~kg} / \mathrm{m} 2$. He looked pale, no icterus, cyanosis, lymphadenopathy and pedal edema. He is afebrile with no any abnormal systemic examination findings.

His heart rate was 100 beats/min, blood pressure was $100 / 70 \mathrm{~mm}$ of $\mathrm{Hg}$ at the time of arrival. Rest all vitals are within normal limits. 


\section{JMSCR Vol||08||Issue||02||Page 57-60||February}

His laboratory parameters were as follows:

Haemoglobin $=6.3 \mathrm{~g} / \mathrm{dl}, \mathrm{TWBC}=4700$ cells $/ \mathrm{mm} 3(\mathrm{~N}-$ 50, L-44, M-03,E-03) RBC=3.06Lac/mm3, Haematocrit $=34 \%, \mathrm{MCV}=111.2 \mathrm{fl}, \mathrm{MCH}=29.8 \mathrm{pg}$, $\mathrm{MCHC}=26.8 \mathrm{~g} / \mathrm{dl}, \mathrm{RDW}=20.2$, Platelets $=2,00,000$ cells/mm3.Peripheral

smear examination: RBC-erythrocytopenia with normocytic normochromic cells, WBC-leucopenia with normal morphology, Platelets-normal in number, RBS $=125 \mathrm{mg} / \mathrm{dl}$. RFT: $\mathrm{BUN}=23 \mathrm{mg} / \mathrm{dl}$ Serum Creatinine $=0.5 \mathrm{mg} / \mathrm{dl}, 24$ hour urine protein $=120 \mathrm{mg}$, UPCR $=0.7$ Rheumatoid factor $\mathrm{IgM}$ ELISA=negative, ANA $=4+$ homogenous pattern ANTI-ds DNA Ab's $=\operatorname{POSITIVE(2.6),~bone~}$ marrow-normal, USG abdomen- normal, 2D EchoGood B/V function, no RWMA, no PE, no clot

\section{UGI endoscopy- Vascular Ectasia Found in the Antrum}

Treatment: the patient was treated with UGI endoscopy and GOLD probe ablation. Blood transfusion was done
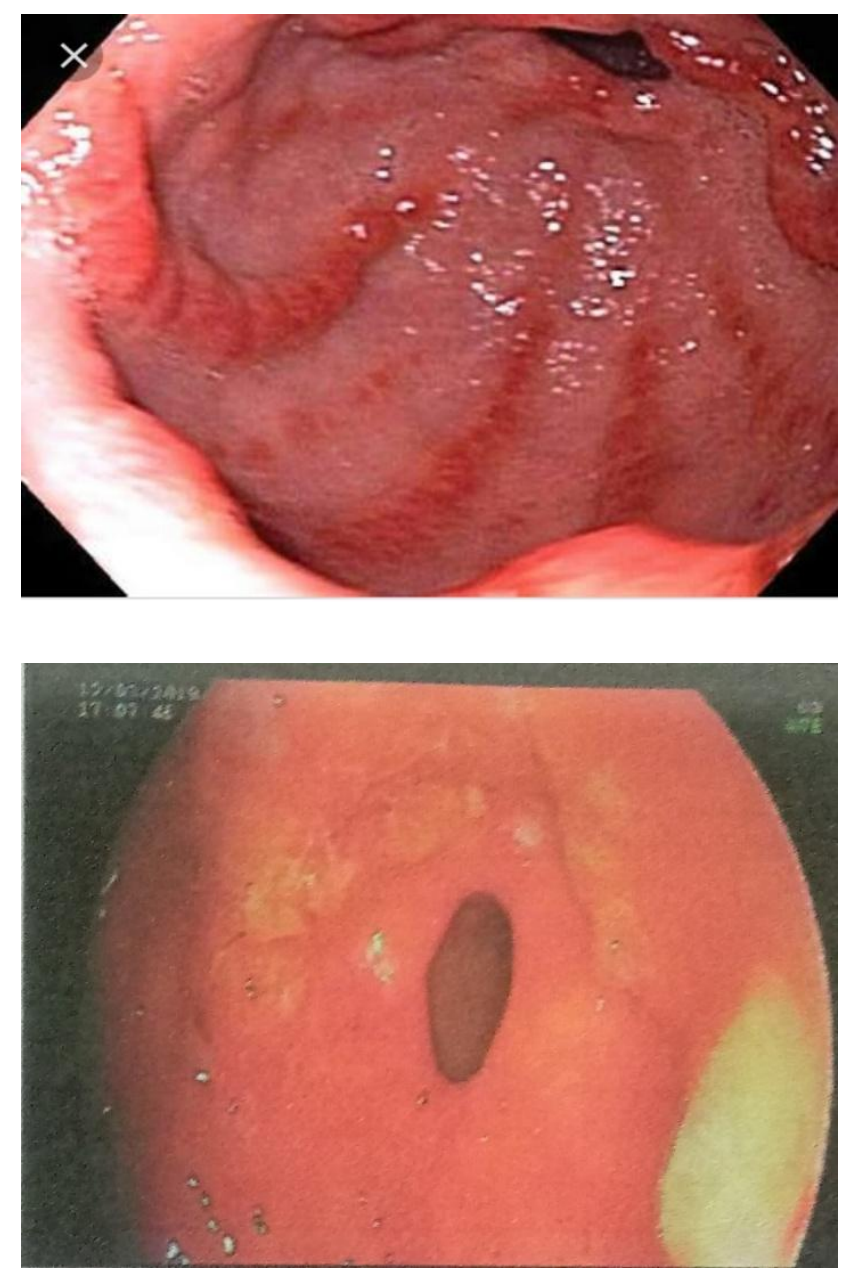

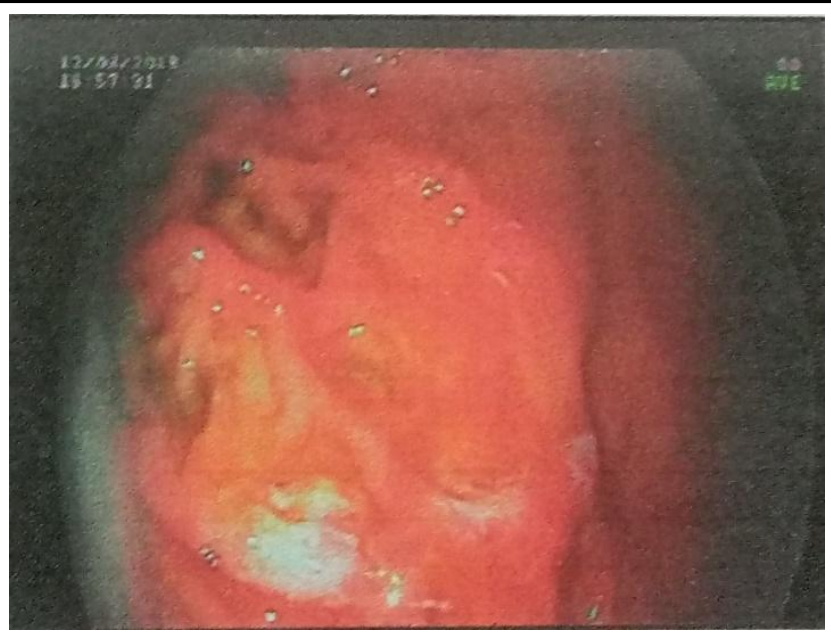

\section{Discussion}

The clinical presentation of SLE is different in different patients. It can affect many organ systems over the course of the disease at different times. Hence the diagnosis of lupus a challenge for clinicians due to its multiple organ involvement. Some manifestations, such as musculo-skeletal and cutaneous signs, are common and unique to SLE. Organ specific inflammation (renal, pulmonary or gastro-intestinal) can mimic other related conditions. It will cause delay in disease recognition and treatment. Hence the morbidity and mortality in SLE was quite significant.

The focus of this review was to analyze the effects of SLE on the gastrointestinal tract. In SLE any part of the GIT from mouth to anus can involve, that can cumulatively affect $25-40 \%$ of all SLE patients. It is always important to distinguish SLE GI manifestations from both other disease processes and from side effects of medications used to treat the primary disease. It help the clinician recognize the presence of SLE which will give the patient the best opportunity to treat and alleviate their effects. This is very important for patients to reduced disease related morbidity and mortality.

The involvement of various parts of gastro intestinal tract in SLE is varied.

Oral cavity- three variants of oral lesions can be seen, discoid, erythmatous, ulcer like. These oral lesions may be painful or painless ${ }^{[4]}$

Esophagus - dysphagia due to impaired motility involving upper $1 / 3^{\text {rd }}$ of esophagus (as per some studies) probably due to vasculitic process in the 
smooth muscles or nerve of auerbach plexus. ${ }^{[5]}$ The other possible cause of dysphagia can be GERD.

Stomach- gastritis and peptic ulcer disease are the most common manifestations due to stomach involvement in SLE. ${ }^{[6]}$ The strong association is due to chronic usage of anti inflammatory drugs.

NSAIDs have long been associated with the development of Peptic Ulcer Disease (PUD) from their inhibition of prostaglandin synthesis. Few SLE patients have gastric involvement in the form of pernicious anaemia. $^{[7]}$ GASTRIC VASCULAR ECTASIA (watermelon stomach) being more common in sclerodrma also seen in SLE in association with iron deficiency and vitiigo. ${ }^{[8]}$

The intestinal involvement will be in the form of motility disorder like chronic intestinsl pseudo obstruction, ${ }^{[9]}$ inflammatory bowel disease ${ }^{[10]}$, malabsorption. ${ }^{[11]}$

In our case report the patient was thoroughly evaluated for hematemesis following which he was diagnosed to have gastric vascular ectasia which was a rare vascular gastric involvement in patients with SLE.

\section{Conclusion}

Despite of its rare incidence gastric vascular ectasia should also be considered and thoroughly evaluated for its diagnosis in SLE patients complaining of repeated bouts of hematemesis, even though PUD being more common

\section{References}

1. Bevra Hannahs Hahn systemic lupus erythmatosus Harrison's principles of internal medicine $18^{\text {th }}$ edition McGraw-Hill 2018 p2724

2. Steffan W. Schulz et al, the gastrointestinal manifestations of systemic lupus erythematosus : a survey of the literature The Open Autoimmunity Journal, 2009, 1, $10-26$

3. systemic lupus erythmatosus, autoimmune diseases; Robbins basic pathology $9^{\text {th }}$ edition Elsevier 2016 P125.
4. Tan EM, Cohen AS, Fries JF, et al. The 1982 revised criteria for the classification of systemic lupus erythematosus. Arthritis Rheum 1982; 25: 271-7.

5. Ramirez-Mata M, Reyes PA, AlarconSegovia D, et al. Esophageal motility in systemic lupus erythematosus. Am J Dig Dis1974; 19(2):132-6

6. Hallegua DS, Wallace CJ. Gastrointestinal and Hepatic Manifestations.In: Wallace DJ, Hahn BH, Eds. Dubois' Lupus Erythematosus: 6th ed. Philadelphia: Lippincott Williams and Wilkins 2002; 84357.

7. Junca J, Cuxart A, Olive A, et al. Antiintrinsic factor antibodies in systemic lupus erythematosus. Lupus. 1993; 2(2): 111-4.

8. Archimandritis A, Tsirantonaki M, Tzivras $\mathrm{M}$, et al. Watermelon stomach in a patient with vitiligo and systemic lupus erythematosus. Clin Exp Rheumatol 1996; 14(2): 227-8.

9. Mann SD, Debinski HS, Kamm MA. Clinical characteristics of chronic idiopathic intestinal pseudo-obstruction in adults. Gut 1997; 41(5): 675-81.

10. Lee CK, Ahn MS, Lee EY, et al. Acute Abdominal Pain in SLE: focus on lupus enteritis .Ann Rheum Dis 2002; 61:547-50.

11. Perednia DA, Curosh NA. Lupus-associated protein-losing enteropathy. Arch Intern Med 1990; 150(9): 1806-10. 